Article

\title{
Day-Ahead Probabilistic Model for Scheduling the Operation of a Wind Pumped-Storage Hybrid Power Station: Overcoming Forecasting Errors to Ensure Reliability of Supply to the Grid
}

\author{
Jakub Jurasz ${ }^{1, *(1)}$ and Alexander Kies ${ }^{2, *}$ \\ 1 Department of Engineering Managment, AGH University of Science and Technology, 30-059 Kraków, Poland \\ 2 Frankfurt Institute for Advanced Studies, Goethe University Frankfurt, 60438 Frankfurt am Main, Germany \\ * Correspondence: jakubamiljurasz@gmail.com (J.J.); kies@fias.uni-frankfurt.de (A.K.); \\ Tel.: +48-792-612-485 (J.J)
}

Received: 19 May 2018; Accepted: 11 June 2018; Published: 13 June 2018

check for updates

\begin{abstract}
Variable renewable energy sources (VRES), such as solarphotovoltaic (PV) and wind turbines (WT), are starting to play a significant role in several energy systems around the globe. To overcome the problem of their non-dispatchable and stochastic nature, several approaches have been proposed so far. This paper describes a novel mathematical model for scheduling the operation of a wind-powered pumped-storage hydroelectricity (PSH) hybrid for 25 to $48 \mathrm{~h}$ ahead. The model is based on mathematical programming and wind speed forecasts for the next 1 to $24 \mathrm{~h}$, along with predicted upper reservoir occupancy for the 24th hour ahead. The results indicate that by coupling a 2-MW conventional wind turbine with a PSH of energy storing capacity equal to $54 \mathrm{MWh}$ it is possible to significantly reduce the intraday energy generation coefficient of variation from $31 \%$ for pure wind turbine to $1.15 \%$ for a wind-powered PSH The scheduling errors calculated based on mean absolute percentage error (MAPE) are significantly smaller for such a coupling than those seen for wind generation forecasts, at $2.39 \%$ and $27 \%$, respectively. This is even stronger emphasized by the fact that, those for wind generation were calculated for forecasts made for the next 1 to $24 \mathrm{~h}$, while those for scheduled generation were calculated for forecasts made for the next 25 to $48 \mathrm{~h}$. The results clearly show that the proposed scheduling approach ensures the high reliability of the WT-PSH energy source.
\end{abstract}

Keywords: variable renewable energy sources; hybrid energy sources; scheduling; nondispatchability; reliability

\section{Introduction}

The randomness and high variability of wind power strongly limits its potential to be a reliable energy source. However, its availability in certain parts of the world, its economic superiority over other energy sources, and government-driven financial incentives have all led to it acquiring a significant role in several existing power systems. Due to the limited predictability of wind generation and legal regulations which give priority to wind sources, the operation of conventional power plants must be adjusted not only to varying energy demand, but now also to the fluctuating energy yield from wind turbines.

The problem of forecasting energy demand has been addressed in a great number of scientific papers [1,2] and over time forecasting errors have been significantly reduced. However, with the advent of larger-scale VRES generation this problem has escalated on the supply side of the energy market. The problem of VRES integration has recently been scrutinised by [3-5], whereas [6,7] have summarised 
approaches which can be used to ease and overcome this problem. Those include, inter alia: energy storage; spatial and temporal complementarity of energy sources; demand side management (DMS); hybrid energy sources; vehicle-to-grid (V2G); power generation capacity oversizing; and transmission lines connecting energy systems in different locations. This paper, to some extent, builds upon those concepts and aims to overcome the problem of the inherent variability of wind generation by coupling it with almost the only bulk (and certainly the most mature) form of energy storage in the form of PSH, and by proposing a novel scheduling formula for the next 25 to $48 \mathrm{~h}$.

\subsection{WT-PSH Hybrid Energy Sources}

A great number of scientific papers has been dedicated to the concept of wind turbines operating together with an energy storage facility in the form of PSH. Due to the popularity of this concept as a solution for supplying isolated communities with electricity, the majority of authors focus on WT-PSH hybrids on islands. At least five papers [8-12] have been dedicated to the WT-PSH system on Lesbos Island (the Aegean Sea), with the authors of those papers claiming that such hybrids can significantly increase the utilisation of wind energy and lead to greater penetration by RES, translating into lower consumption of the oil so commonly used in off-grid systems. A paper written by Karsaprakakis et al. [13] points out that Greek law defines the WT-PSH hybrid as a conventional power plant with full dispatchability. In those authors' opinions, such a hybrid energy sources does not have to provide power all the time and its use can be limited to specific periods in order to facilitate the operation of other energy sources. Two more papers [14,15] investigated the WT-PSH concept on Ikaria Island (the Aegean Sea). Similarly, as in our research, the authors of the aforementioned papers have assumed that the available energy from the WT will first be pumped into the upper reservoir and then dispatched when needed. Additionally, the PSH upper reservoir can be, to some extent, supplied by the excess flow from the additional reservoir which is located above it and used for irrigation purposes.

Three papers [16-18] investigated the possibility of covering the energy needs of a local community inhabiting a small island near Hong Kong. The analyses presented in these papers are part of a larger project aiming to ensure total energy autarky by means of a WT-PSH hybrid cooperating with a PV installation. Results note, for example, the environmental aspects of large scale battery banks and the superiority of PSH in this regard.

Some articles have also been dedicated to mainland WT-PSH hybrids. Hessami and Bowly [19] investigated a 190-MW wind farm connected to various forms of energy storage and found the optimal one to guarantee maximal revenue. Of the three considered, namely PSH, compressed air energy storage (CAES), and thermal energy storage (TES), CAES seems to be the most promising in terms of the rate of return (ROR) criterion. Hedegaard and Meilbom [20] analyzed the WT-PSH concept from the perspective of the Danish energy system, where wind generation plays an important role in covering energy needs. According to the authors' results, wind-powered PSHs can both be used as a first-tier reserve power plant with very swift reaction times, and also be applied to compensate for the seasonal variability of WT generation. Canales et al. [21] and Murage and Anderson [22] analyzed the WT-PSH hybrid from the Brazilian and Kenyan points of view, respectively. Canales et al. [21] point out that PSH facilities have larger upfront costs than traditional hydropower plants with pumping installations, but that their operational costs and environmental impact are significantly smaller.

\section{Scheduling WT-PSH Operation}

To the best of the author's knowledge, the issue of scheduling the operation of wind-powered PSH has been the subject of the following papers:

- Varkani et al. [23] proposed the concept of a self-scheduling strategy which is based on stochastic programming techniques and aims to minimise the impact of wind power generation's uncertainty. The strategy presented by the authors can be applied for day-ahead energy generation offers. 
The uncertainty of the wind generation forecasts is modelled by means of an artificial neural network (ANN);

- Tan et al. [24] developed a two-stage scheduling optimisation model for the operation of a wind power and energy storage system based on day-ahead and ultra-short-term wind power forecasting. The results indicate that synergies of demand response and energy storage can be used to overcome wind generation variability and lead to an improvement in utilisation of wind energy, as well as decreasing coal consumption. Similarly, as in [23], the uncertainty of wind power was simulated, in this case being based on a scenario analysis;

- Jurasz and Mikulik [25] suggested a model for scheduling the operation of WT-PSH based on the occupancy of the upper reservoir. It was assumed that the sets of pumps and generators of the PSH can operate simultaneously. The results indicate that WT-PSH operating on such a formula can be a reliable energy source operating as a baseload (with potential modifications regarding when the energy from the upper reservoir should be dispatched). Additionally, the scheduling formula eliminates the occurrence of wind energy rejection. However, the schedule of the WT-PSH operation for the next 1 to $24 \mathrm{~h}$ is known only one hour ahead;

- Castronuovo nd Lopes [26] proposed a model for improving wind parks' operational economic gains by means of PSH facilities. Using an hourly-discretised algorithm the authors identified an optimal daily operation strategy assuming that wind power forecasts were available; and

- Papaefthimiou et al. [27] suggested several possible operation modes for WT-PSH focusing on their verbal description. In general: the WT-PSH can submit an energy offer for the next $24 \mathrm{~h}$ considering the state of charge of its upper reservoir; the system operator dispatches the PSH operation mainly during peak load hours or to shave the peaks; the energy generated by the WT is stored in the upper reservoir and the PSH pumps balance the varying WT energy yield-basically, using variable-speed pumps the PSH is able to constantly adjust to the changes in wind generation; the system operator requires the WT-PSH to deliver power in certain periods in order to fill deficits resulting from the limited capacity of the conventional power sources; and the WT-PSH is designed to deliver guaranteed power, but if the upper reservoir state of charge is not sufficient and/or the wind generation forecasts are unfavourable then it is admissible to use electricity from the grid and dispatch it when required. According to their results, the authors state that the proposed operating policies enable the integration of wind generation on a larger scale.

Clearly this problem is investigated in the literature, but the number of papers and approaches is limited. The authors of the aforementioned papers have investigated the problem of WT-PSH operation from different perspectives. Therefore, the ability to draw general conclusions is constrained. The common denominator of the majority of those papers is that the authors point to the relevance of the accuracy of wind speed forecasts and the increasing role of wind generation in today's power systems.

\subsection{Wind Speed Forecasting}

As mentioned by [6,7] and the authors of the papers presented in Section 1.1 [23-28], forecasting techniques are a possible tool for smoothing the integration of variable renewable energy sources into the power system. Additionally, accurate forecasts with low absolute and percentage errors can make the process of scheduling the operation of conventional power plants more accurate and economically feasible.

Soman et al. [29] provided an overview of current wind power and wind speed forecasting methods with different time horizons. Depending on the application, the wind forecasting can be divided into four time horizon categories: very short term forecasting (from seconds to $30 \mathrm{~min}$ ahead), short term forecasting (from $30 \mathrm{~min}$ to $6 \mathrm{~h}$ ahead), medium term forecasting (from $6 \mathrm{~h}$ to 1 day ahead), and long term forecasting (ranging from one day ahead to one week ahead). The ranges of individual categories are not fixed and can be modified. From the above we conclude that the scheduling formula proposed in Section 2.2. would be based on a combination of short and medium-term forecasting. 
Advances in computing power, as well as deeper and broader understanding of various phenomena, have led to the rapid development of various forecasting tools and approaches [30]. The majority of them are also being used in the area of wind speed forecasting. The most commonly-applied techniques are based on: persistence methods/naïve predictors, which are usually used as benchmarks; physical approaches, which use numerical weather predictors (NWP); statistical approaches based on time series analysis or artificial neural networks (ANN); and emerging methods based on wavelet transformation or fuzzy logic (hybrid approaches which develop new hybrid tools which utilise various combinations of, for example, ANN + wavelet transformation or ANN + fuzzy logic).

Recently published papers have mostly concentrated on various hybrid approaches [31-33] and investigated the impact of various phenomena, such as the spatial distribution on forecasts' error correlation [34]. The abundance of literature and the presence of various concepts and tools for forecasting wind speed or wind power shows the complexity of this problem and proves its importance in the context of the VRES integration into the power system. As an example of papers which clearly show the complexity of VRES integration which applied dynamic programing to overcome the problems of models non-linearity and non-convexity we refer the reader to the works of Korkas et al. [35] and Baldi et al. [36]. Other examples of wind-solar or solar integration by means of hydropower to the national power system can be found in [37-39].

In this paper we do not aim to develop a new method or apply the existing ones. The potential user of our scheduling approach can arbitrarily select the forecasting methods which best suits his needs or are the best available solution for the location of a given wind farm. Such aspects of wind speed forecasting and the role of their accuracy in RES-based hybrid energy sources has been investigated in [40]. For the purpose of this paper the forecasting errors have been generated based on the assumption of their normal distribution and percentage value increasing with an elongating time horizon-detailed information on this is provided in Section 3.2.

\subsection{WT-PSH}

The main idea behind the scheduling concept introduced in this paper is that it is possible to overcome the inherent variability of wind energy by using the storage capacity of the upper reservoir to offset the inaccuracy of wind speed forecasts. The conceptual design of the wind powered PSH has been presented in Figure 1.

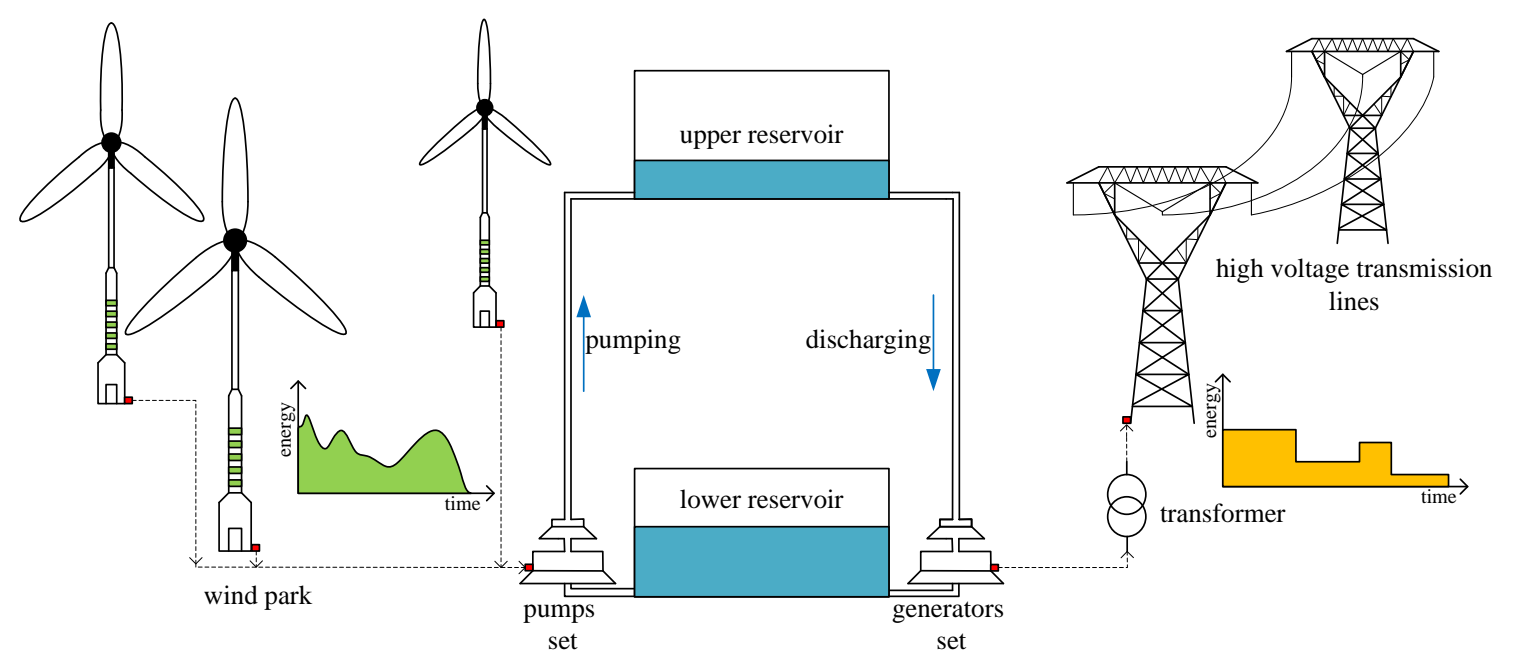

Figure 1. Conceptual design of WT-PSH hybrid along with energy and water flows and schematic charts visualising the initial and resulting variability of energy generation. 
The operation of such a system is based on day-ahead schedules created to determine the volume of energy which should be discharged over the next 25 to $48 \mathrm{~h}$. The energy available from the WTs is always firstly stored in the upper reservoir. Naturally, the situation may occur in which the reservoir is full and some portion of WT-derived energy will have to be fed to the grid. Such situations, as well as partially realised schedules, should be avoided because they introduce undesirable disruptions into the operation of the energy market.

\subsection{Paper Objectives}

Considering the aspects and potential role of WT-PSH hybrid energy sources described above, this paper aims to realise the following goals:

- to develop a MINLP model for simulating the operation of the WT-PSH hybrid and scheduling its operation;

- to establish measures for estimating the model's accuracy; and

- to investigate the impact of the scheduling formula parameters and upper reservoir capacity on WT-PSH performance.

\section{Mathematical Model}

In this paper we have used a mathematical model which has been used for a discretised hourly wind speed time series and can be applied in various simulation and optimisation software packages.

\subsection{Energy Yield from Wind Turbines}

The energy generated by a wind turbine can be estimated based on the known wind speed and the power curve of a given type of wind generator. Here, a commonly-applied Gamesa G90 [41] wind turbine has been selected for simulation purposes. Figure 2 visualises its power curve for wind speeds ranging from $3 \mathrm{~m} / \mathrm{s}\left(v^{\text {cut-in }}\right)$ to $12 \mathrm{~m} / \mathrm{s}\left(v^{\text {rated }}\right)$, with the operation of WT being stopped when the wind speed exceeds $25 \mathrm{~m} / \mathrm{s}\left(v^{\text {cut-off }}\right)$. In the model introduced in Section 2.2, the equation is used to calculate the actual (EWT) and forecasted (EWT*) energy yield from wind. For the forecasted values, predicted wind speeds $\left(v^{*}\right)$ were used as shown in Section 3.2.

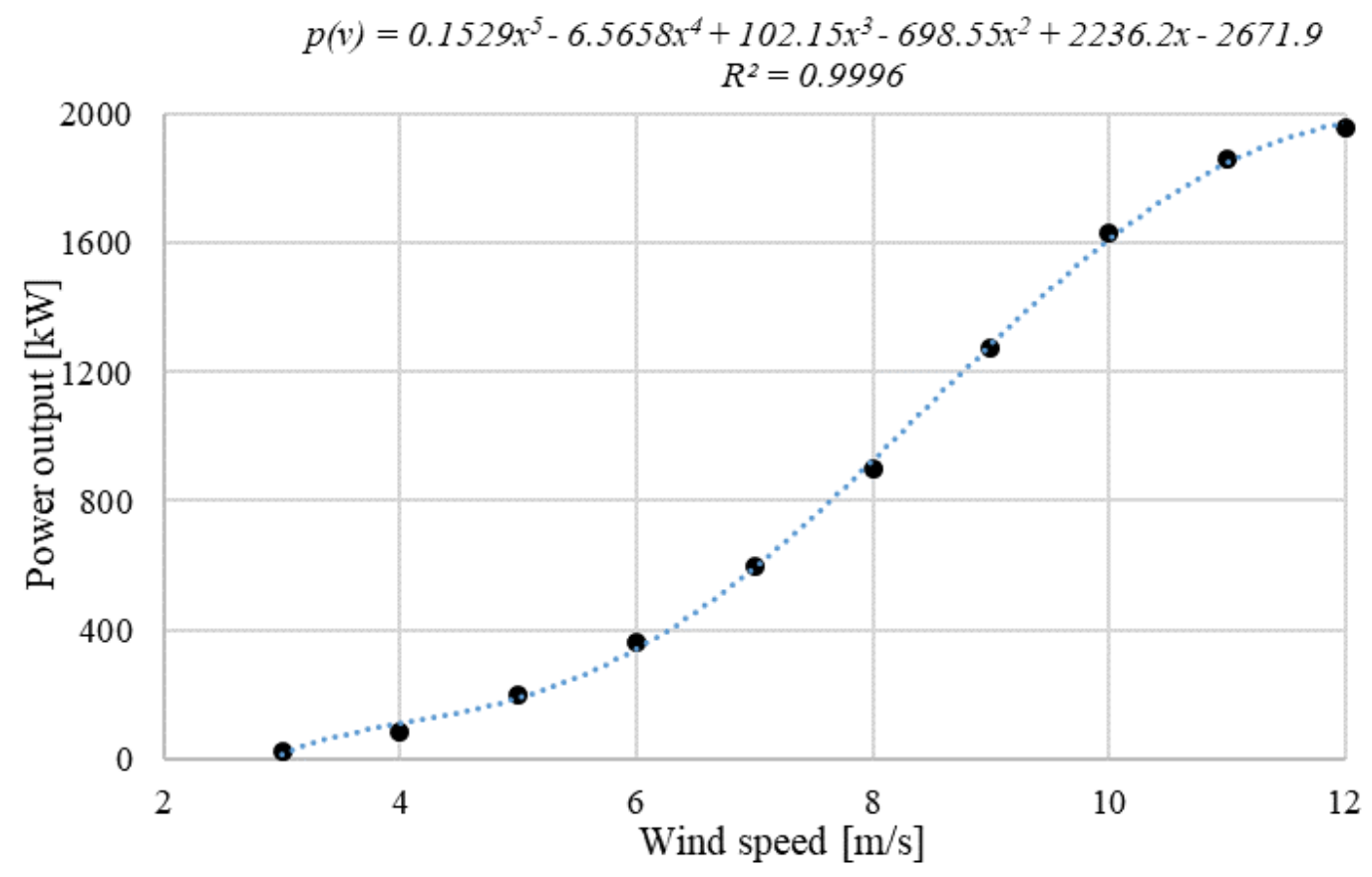

Figure 2. The Gamesa G90 power curve. 


$$
E^{W T}=\left\{\begin{array}{c}
P^{W T} \times t \times n \text { for } v \in\left\langle v^{\text {rated }} ; v^{\text {cut }-o f f}\right) \\
p(v) \times t \times n \text { for } v \in\left\langle v^{\text {cut }- \text { in }} ; v^{\text {rated }}\right) \\
0 \text { otherwise }
\end{array}\right.
$$

where $E^{W T}$ is the energy yield from wind turbine $(\mathrm{kWh}), P^{W T}$ is the nominal capacity of wind turbine $(\mathrm{kW}), t$ is the time $(1 \mathrm{~h}), n$ is the number of wind turbines $(-), v^{\text {rated }}$ is the wind speed at which the wind turbine starts to operate with its nominal capacity $(\mathrm{m} / \mathrm{s}), v^{\text {cut }-o f f}$ is the wind speed at which turbine operation is stopped for safety reasons $(\mathrm{m} / \mathrm{s}), p(v)$ is the polynomial approximating wind turbine power curve $(\mathrm{kW})$, and $v^{\text {cut-in }}$ is the wind speed at which wind turbine starts to generate electricity $(\mathrm{m} / \mathrm{s})$.

\subsection{WT-PSH Operation}

In this section we introduce and describe the approach used to schedule the operation of the WT-PSH. In the following paragraphs it is visualised in Figure 3, a verbal algorithm and a mathematical formulation.

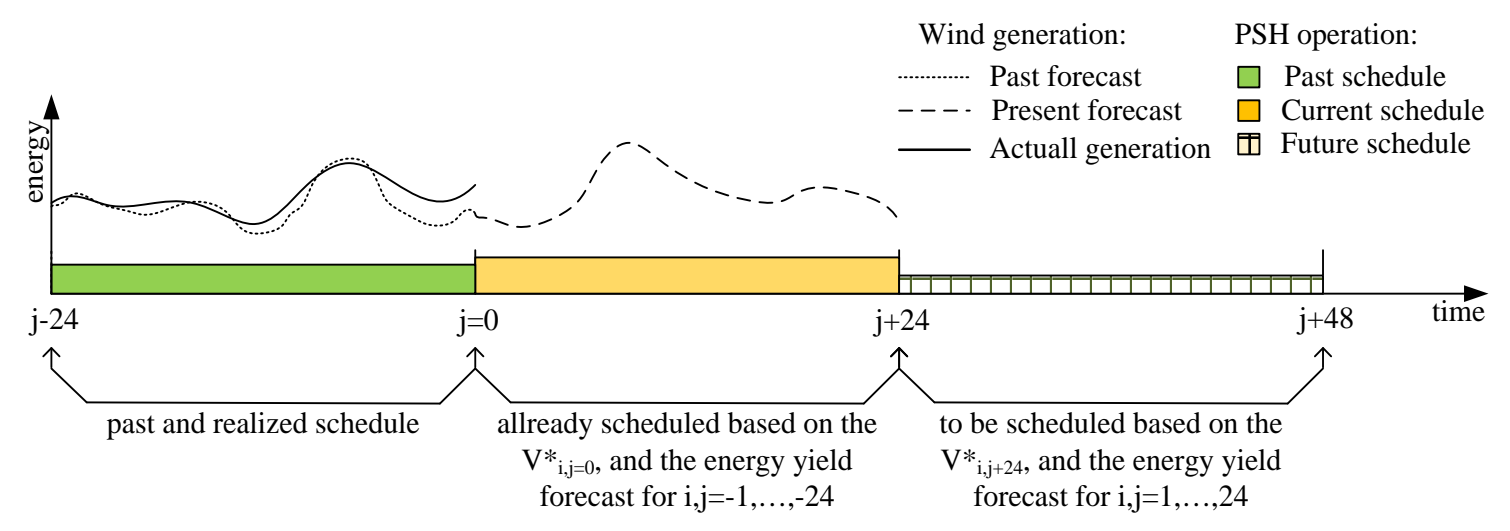

Figure 3. Chart depicting the WT-PSH scheduling method.

\section{WPSH Operation}

Generally speaking, the schedule creation procedure can be summarised in the five steps listed hereunder:

Step 1. Obtain/generate wind turbine energy yield forecast for the next $24 \mathrm{~h}$.

Step 2. Determine the upper reservoir state of filling at the end of the upcoming day $(j=24)$ based on the already scheduled discharge covering the next $24 \mathrm{~h}(j=1, \ldots, 24)$ and possible energy generation from wind turbines calculated in the first step.

Step 3. Considering the estimated reservoir occupancy of the upper reservoir in step 2, generate a uniform discharge schedule for the next 25 to $48 \mathrm{~h}(j=25, \ldots, 48)$.

Step 4. After realising the previously-planned schedule for the period $(j=1, \ldots, 24)$ juxtapose the scheduled and actual operation of the PSH as well as the wind turbine generation and upper reservoir occupancy. In case of any discrepancies replace the estimated occupancy of the upper reservoir calculated in step 2 by the actual one.

Step 5. Return to the step 1 and repeat the whole procedure.

The verbal description of the procedure described above can also be expressed by means of several mathematical formulas and equations. As mentioned earlier the first step is to determine the volume of energy stored in the upper reservoir. Here, an assumption has been made that the initial reservoir occupancy $(i=1, j=0)$ is half its maximal capacity. It is important to emphasise that, for simulation 
purposes, we have been simultaneously calculating the reservoir occupancy for a scheduled PSH operation and forecasted wind power generation (Equation (2)), as well as for actual PSH operation and actual WT energy yield (Equation (3)). This was done in order to assess the accuracy and quality of the proposed scheduling approach. Such an approach is necessary due to the intermittent nature of wind generation and the non-ideal accuracy of wind generation forecasts. The idea behind Equations (2) and (3) is as follows: within each unit of time (hour) a certain volume of energy is being discharged from the upper reservoir and, simultaneously, some energy from wind generation is being pumped upwards. The calculating procedure must ensure that the characteristics of the PSH will not be exceeded, meaning that the calculated momentary volume of energy stored in the upper reservoir is not smaller than zero or greater than its maximal storage capacity. Additionally, the momentary energy storage capacity of the PSH is limited by the throughput of its pumps; therefore, from the available wind generation only a volume ranging from 0 to $E^{\text {Pump }}$ can be considered as possible for storing:

$$
\begin{aligned}
V_{i, j}^{*} & =\min \left(\max \left(V_{i, j-1}^{*}-E_{i, j}^{C} \frac{1}{\eta^{\text {PSH }}}+\min \left(E_{i, j}^{\text {WT* }} \eta^{\text {PSH }} ; E^{\text {Pump }}\right) ; 0\right) ; V^{M}\right) \\
V_{i, j} & =\min \left(\max \left(V_{i, j-1}-E_{i, j}^{C} \frac{1}{\eta^{\text {PSH }}}+\min \left(E_{i, j}^{\text {WT }} \eta^{\text {PSH }} ; E^{\text {Pump }}\right) ; 0\right) ; V^{M}\right)
\end{aligned}
$$

where: $V_{i, j}^{*}$ is the forecasted volume of energy stored in the upper reservoir $(\mathrm{kWh}), V_{i, j}$ is the actual volume of energy stored in the upper reservoir $(\mathrm{kWh}), E_{i, j}^{C}$ is the scheduled energy generation from the $\mathrm{PSH}(\mathrm{kWh}), \eta^{P S H}$ - pumping or generating efficiency of the PSH [\%], $E_{i, j}^{W T *}$ is the forecasted energy yield from the wind generation $(\mathrm{kWh}), E^{\text {Pump }}$ is the maximal energy throughput of the PSH pumps $(\mathrm{kWh})$, and $V^{M}$ is the PSH upper reservoir energy storing capacity (kWh).

In Equations (2) and (3) we have used the scheduled PSH generation value $\left(E_{i, j}^{C}\right)$. This can be calculated based on Equation (4) which is the most important part of the presented scheduling method. The schedule for the next 25 to $48 \mathrm{~h}(i+2, j=1, \ldots, 24)$ is generated based on the estimated occupancy of the upper reservoir and the predicted energy yield from wind turbines. Consequently, the exact volume of the available energy for the next considered scheduling period is uncertain. Therefore, to the proposed formula we have introduced two additional parameters $(\beta, \alpha)$ whose potential values are from 0 to 1 . Their main task is to compensate for the inaccuracy of the estimated available energy in the upper reservoir $(\beta)$ and the energy yield from wind turbines $(\alpha)$. It is important to highlight that the scheduling formula introduced in Equation (4) leads to a uniform (uniform in theory only, due to forecasting errors) energy generation from the PSH over the next 25 to $48 \mathrm{~h}$. Those generation values will be known a day ahead. Equation (4) also ensures that the scheduled energy discharge from the PSH will not be greater than its energy generating capacity $\left(E^{G e n}\right)$.

Naturally, those energy generation patterns can be modified in such a manner that the PSH will generate electricity only during demand peak hours, only during daylight, or over periods when the energy price is highest, thereby increasing the owner's revenue:

$$
E_{i+2, j=1, \ldots, 24}^{C}=\min \left(\min \left(\frac{V_{i+1, j=24}^{*}}{24} \eta^{P S H} ; E^{G e n}\right) \beta+\min \left(\frac{\sum_{j=1}^{24} E_{i+1, j}^{W T *}}{24} \eta^{P S H} ; E^{G e n}\right) \alpha ; E^{G e n}\right)
$$

As already mentioned, the scheduling formula is prone to forecasting errors and periods may consequently occur during which the WT-PSH hybrid is unable to realise the created energy generation schedule. Therefore, to assess the quality of our approach we have introduced Equation (5), which determines whether the schedule was realised or not and what the actual electricity generation $\left(E_{i, j}^{C R}\right)$ was in comparison to that scheduled $\left(E_{i, j}^{C}\right)$ :

$$
E_{i, j}^{C R}=\left\{\begin{array}{c}
E_{i, j}^{C} \text { for } V_{i, j-1} \geq E_{i, j}^{C} \frac{1}{\eta^{P S H}} \\
V_{i, j-1} \eta^{P S H} \text { otherwise }
\end{array}\right.
$$


In the case of non-dispatchable energy sources coupled to the national power system (NPS) or any other type of grid, two distinctive situations may occur. Namely, energy generation is less than demand (in this paper the scheduled generation is as shown in Equation (5)) and an energy deficit occurs which should be covered by any other energy source or, alternatively, available energy is greater than demand and an energy surplus appears. In the case of the WT-PSH some part of the excess energy which has not been used in the scheduled generation can be stored in the upper reservoir. However, this is limited by the maximal capacity of the reservoir and, consequently, sometimes some volume of energy coming from WT may be neither used in the PSH generation schedule nor stored. This energy is rejected and its volume $\left(E_{i, j}^{W T_{-} R}\right)$ can be calculated based on Equation (6). By rejection we mean a direct transfer of that energy to the grid-a situation which is not desirable because it increases variability and unpredictability on the energy market. The problem of an unexpected energy flow between hybrid energy sources based on PV and WT coupled with the PSH and the NPS has been investigated in [42] where it is revealed that, to some extent, they can be quite accurately forecasted:

$$
E_{i, j}^{W T-R}=\left\{\begin{array}{c}
E_{i, j}^{W T} \eta^{P S H}-E^{\text {Pump }} \text { for } E_{i, j}^{W T} \eta^{P S H}>E^{\text {Pump }} \\
E_{i, j}^{W T}-\left(V^{M}-\left(V_{i, j-1}-E_{i, j}^{C} \frac{1}{\eta^{P S H}}\right)\right) \text { for } V_{i, j-1}-E_{i, j}^{C} \frac{1}{\eta^{P S H}}+E_{i, j}^{W T} \eta^{P S H}>V^{M} \\
\text { otherwise }
\end{array}\right.
$$

The situations described by Equations (5) and (6) are both undesirable events which should be avoided. Therefore, their volumes and occurrences will be the subject of the optimisation model introduced in Section 3.2.

\section{Input Data}

\subsection{Wind Data}

For simulation purposes, an hourly time series of wind speed data covering the years 2014-2016 for the Koszalin measuring station (Northern Poland-10 km straight-line distance from the Baltic Sea) was downloaded from [43]. Figure 4 visualises the variability of considered wind speeds.

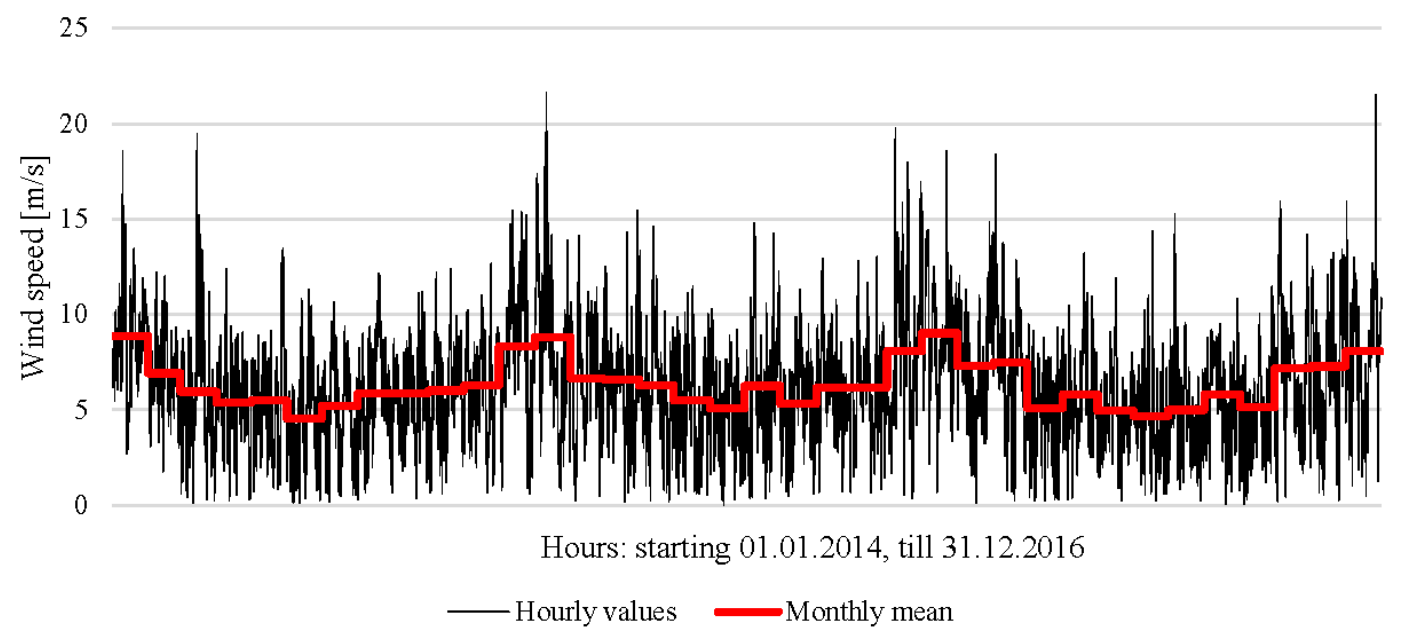

Figure 4. Wind speed variability over the 2014-2016 period.

\subsection{Wind Speed Forecast Accuracy}

Since no historical records on wind speed forecast quality were available, synthetic forecasts were generated based on the assumption that with the extending prediction horizon the accuracy of the forecast deteriorates. It is important to emphasise that the approach used here was made only for demonstration purposes and the assumptions of forecast mean error values and standard deviation 
of errors for each prediction horizon were determined arbitrarily. Naturally, in reality, better quality forecasts can be employed and, as a consequence, the proposed approach can be used as a benchmark. Figure 5 visualises the MAPE (mean absolute percentage error) values of errors for various time horizons. When the simulations were run, the average MAPE error over the whole considered period for forecasts ranging from 1 to $24 \mathrm{~h}$ ahead was $27 \%$.

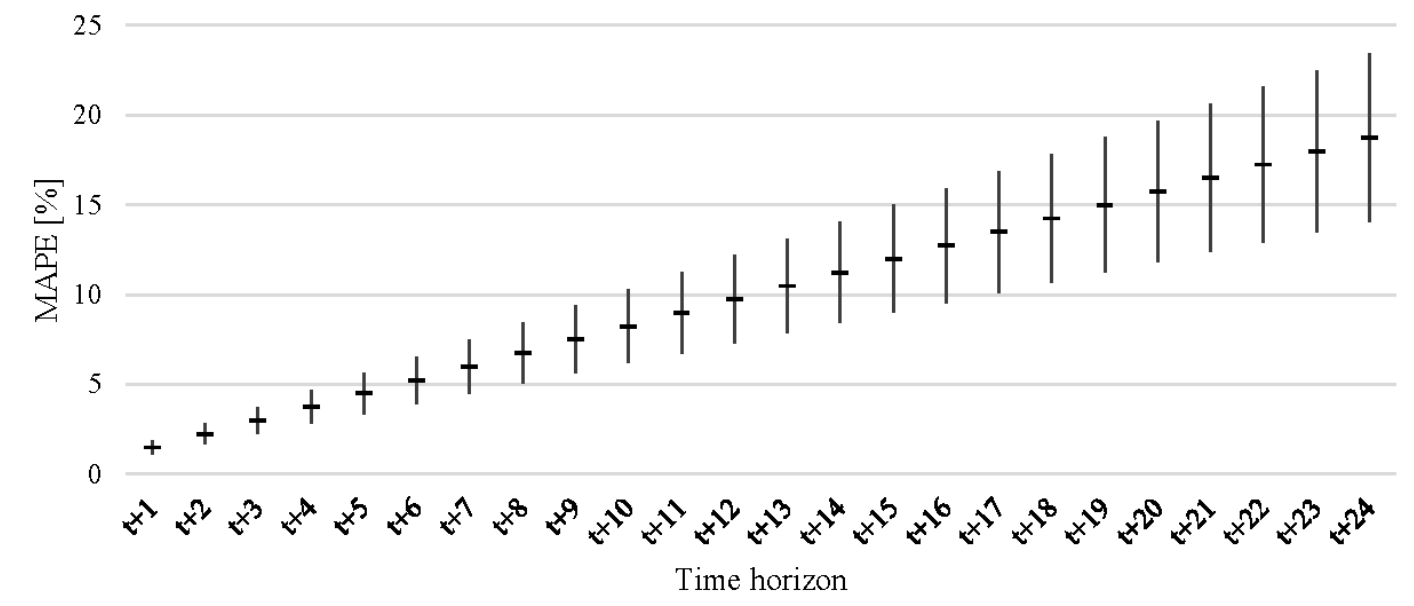

Figure 5. Forecast errors and their range for various prediction time horizons. The errors are normally distributed.

\subsection{WT-PSH Parameters}

For simulation purposes we have assumed that the WT-PSH hybrid will consist of a single wind turbine with a rated capacity of $2 \mathrm{MW}$ coupled to a PSH facility which has a set of pumps capable of accommodating the maximal hourly yield from the WT. The power output of the water turbines used to generate electricity is equal to the set of pumps and is $2 \mathrm{MW}$. The energy storage capacity of the PSH (the volume of the upper reservoir) will be the subject of sensitivity analysis, with the minimal storage capacity calculated as $V^{M}=24 \times 1 / 2 \times \eta^{P S H} \times P^{T W}$, or in words, half of the energy generated by the WT operating for $24 \mathrm{~h}$ at nominal capacity and taking into account the efficiency of the PSH pumps. The considered cycle efficiency of the PSH was $81 \%$.

\section{Results and Discussion}

For the considered wind speed conditions, the 2 MW Gamesa G90 wind turbine should generate $5.33 \mathrm{GWh}$ of electricity annually, which translates into a capacity factor of $30 \%$. For the forecast quality presented in Section 3.2 the mean absolute forecast error was $131 \mathrm{kWh}$, while the lowest and highest were $0 \mathrm{kWh}$ and $2000 \mathrm{kWh}$, respectively. Considering above in our analysis we have considered a WT-PSH hybrid which is characterized by the following parameters: a 2 MW Gamesa G90 wind turbine will be directly coupled with the PSH pump which is characterized by a $90 \%$ efficiency and installed capacity of $2 \mathrm{MW}$; the PSH generates electricity by means of hydro unit of $2 \mathrm{MW}$ rated capacity and efficiency of $90 \%$; the PSH upper reservoir storage capacity is subject of change and varies from 21.6 MWh to $172.8 \mathrm{MWh}$ (with an increment of $10.8 \mathrm{MWh}$ ); the capacity of the lower reservoir is in the considered case not subject of analysis and was considered as infinite (or significantly larger than the upper reservoir).

\subsection{WT-PSH Parameters}

The accuracy of the introduced scheduling approach was assessed based on the MAPE criterion, whose value can be calculated from Equation (7). This criterion was further used in the optimisation model: 


$$
\operatorname{MAPE}=\frac{1}{m n} \sum_{i=1}^{m} \sum_{j=1}^{n}\left|\frac{E_{i, j}^{C}-E_{i, j}^{C R}}{E_{i, j}^{C}}\right| 100 \%
$$

The precision of day-ahead predictions of the available quantity of produced energy was optimised by finding the minimal value of Equation (7) by changing the values of $\alpha$ and $\beta$ parameters, which are part of the scheduling formula (Equation (4)) while also ensuring that the volume of the rejected energy from wind generation will not be greater than the constant value $R$ (Equation (8)). In this case, $R$ was arbitrarily equal to $5 \%$ :

$$
\sum_{i=1}^{m} \sum_{j=1}^{n} E_{i, j}^{W T \_R} \leq R .
$$

To find the optimal solution a brute-force method was applied and the subs of possible pairs of $\alpha$ and $\beta$ parameters was limited by assuming that their values would range from $\langle 0 ; 1\rangle$ with an increment of 0.1. Optimal and acceptable solutions were found for all considered upper reservoir capacities, which ranged from 21.6 to $172.8 \mathrm{MWh}$ with an increment of $10.8 \mathrm{MWh}$. In total, 1815 various configurations of these three variables have been considered and 1356 (almost 75\%) satisfied the imposed constraint given in Equation (8). Additional calculations revealed that by considering $R=2.5 \%$ this number dwindles to 1280 and to 1218 for $R=1 \%$. From the configurations which satisfied the constraint imposed in Equation (8) only one configuration for each capacity of the upper reservoir which exhibited the lowest objective function value (MAPE) was selected. The results are given in Table 1.

First of all, it is important to highlight that the coefficient of variation $(\mathrm{CV})$ calculated for the wind turbine energy generation hourly time series is $101 \%$, whereas for the intraday values it is $38 \%$. Here we understand the intraday variability as the changes in energy generation which occurred within a single day. It is important to emphasise that such variability will have to be considered by the power system operator in scheduling the operation of the conventional power plants. However, by introducing the approach proposed in this paper those variations, and especially the intraday ones, can be significantly reduced.

Analysis of the results presented in Table 1 reveals that for relatively small capacities of the upper reservoir (S1-S4) the imposed constraint $(R<5 \%)$ resulted in an increase in the observed discrepancies between the scheduled and realised operation of the PSH (this is indicated by the value of the MAPE criterion). In scenario S1, which considered the smallest capacity of the upper reservoir (equal to the half of the daily energy generation of the WT with its maximal capacity), we observed an increase in $\mathrm{CV}$ values for the hourly generation values (by $8.5 \%$ relative to the purely wind turbine generation) and a significant reduction in the intraday $\mathrm{CV}$. The $\mathrm{CV}$ values calculated for the hourly time series over the whole considered period describe the general variability of the observed phenomena, whereas the intraday values point to the quality of the scheduling formula. In the best-case scenario, the CV values for the intraday energy generation should be equal to or close to zero. Such can be observed in scenarios S5-S15 which considered greater capacities of the upper reservoir. Therefore, the general conclusion is quite straightforward and common in the area of variable renewable energy sources: with an increasing upper reservoir capacity, the accuracy/realisability of generated schedules increases. This is indicated by the decreasing values of the MAPE and CV criteria.

In the scheduling formula the $\alpha$ parameter dictates to what extent wind energy generation forecasts should be considered in the scheduling procedure, whereas the $\beta$ parameter refers to the forecasted upper reservoir state of filling. Interestingly (as shown in Table 1), for the small upper reservoir capacities (S1-S4) the optimal scheduling formula is almost entirely based on the value of the predicted upper reservoir state of filling, whereas the role of the WT forecasts for the next $24 \mathrm{~h}$ is neglected for $\alpha \leq 0.2$. This indicates that the upper reservoir is, to the same extent, capable of offsetting the inaccuracies in the wind generation forecasts. However, its limited capacity will often lead to situations in which an unreasonable (to bulk energy generation) schedule will ultimately deplete the reservoir or, conversely, the wind generation forecasting errors will lead to the inability of the upper reservoir to store excess energy which has not been considered in the schedule. 
When the capacity of the upper reservoir is greater than $54 \mathrm{MWh}$, this tendency changes, and for scenarios S5-S9 the $\alpha$ is equal to 0.9 and for the remaining ones (S10-S15) it is 0.7. The greater alpha parameter and smaller beta (for S5-S9, $\beta=0$ and for S10-S15, $\beta=0.1$ ) mean that the upper reservoir capacity assumed in those scenarios is sufficient to compensate for the variability and inaccuracy of the wind generation forecasts. From the results presented in Table 1 we can also observe that increasing the upper reservoir capacity above 75.6 MWh does not significantly decrease the values of the MAPE and $\mathrm{CV}$ parameters. In general, by introducing the proposed scheduling formula we were able to reduce:

- the unpredictability of the wind generation from 27\% (MAPE error for the wind generation forecasts) to less than $1.5 \%$ for scenarios S6-S15;

- the hourly variability of the wind generation time series by at least $10 \%$, as in scenarios S2-S9, or almost $23 \%$, as in scenarios S10-S15; and

- the intraday variability from $31 \%$ to less than $1 \%$, as in scenarios S5-S10.

The last result is the most important contribution of the concept introduced in this paper. By combining WTs with the PSH, and applying an appropriate scheduling approach to them, we have obtained a dispatchable energy source with a known energy output for the next 25 to $48 \mathrm{~h}$.

Table 1. Optimal values of $\alpha$ and $\beta$ parameters for various upper reservoir capacities and $R \leq 5 \%$.

\begin{tabular}{ccccccc}
\hline \multirow{3}{*}{ Scenario } & \multicolumn{3}{c}{ Variables } & & & \multicolumn{2}{c}{ CV [\%] } \\
\cline { 2 - 3 } & $\boldsymbol{V}^{\boldsymbol{M}}$ & $\boldsymbol{\alpha}$ & $\boldsymbol{\beta}$ & Mape [\%] & Hourly & Intraday \\
\hline S1 & 21.6 & 0.2 & 1 & 17.63 & 109.48 & 15.84 \\
S2 & 32.4 & 0.1 & 1 & 4.85 & 90.78 & 2.31 \\
S3 & 43.2 & 0.3 & 1 & 3.20 & 90.05 & 1.86 \\
S4 & 54.0 & 0.1 & 1 & 2.39 & 90.02 & 1.15 \\
S5 & 64.8 & 0.9 & 0 & 1.73 & 88.36 & 0.76 \\
S6 & 75.6 & 0.9 & 0 & 1.37 & 88.22 & 0.61 \\
S7 & 86.4 & 0.9 & 0 & 1.15 & 88.05 & 0.43 \\
S8 & 97.2 & 0.9 & 0 & 1.15 & 88.05 & 0.43 \\
S9 & 108.0 & 0.9 & 0 & 1.15 & 88.05 & 0.43 \\
S10 & 118.8 & 0.7 & 0.1 & 1.10 & 78.37 & 0.27 \\
S11 & 129.6 & 0.7 & 0.1 & 1.10 & 78.37 & 0.27 \\
S12 & 140.4 & 0.7 & 0.1 & 1.10 & 78.37 & 0.27 \\
S13 & 151.2 & 0.7 & 0.1 & 1.10 & 78.37 & 0.27 \\
S14 & 162.0 & 0.7 & 0.1 & 1.10 & 78.37 & 0.27 \\
S15 & 172.8 & 0.7 & 0.1 & 1.10 & 78.37 & 0.27 \\
\hline
\end{tabular}

The varying capacity of the upper reservoir not only has an impact on the accuracy of the scheduling formula, but also determines the mean scheduled volume of energy. Figure 6 visualises this phenomena and indicates that for reservoir capacities equal to or greater than $54 \mathrm{MWh}$ the mean scheduled generation ranges from 489 to $491 \mathrm{kWh}$. For the scenarios with smaller upper reservoir capacity (S1-S3) those values were smaller by 20 to $30 \mathrm{kWh}$. This shows that an increase in reservoir capacity above a certain value (here, $54 \mathrm{MWh}$ ) does not contribute to an increase in mean scheduled generation (values ranging from 489 to $491 \mathrm{kWh}$ are exactly equal to the mean generation of the wind turbines which, for the considered location, were equal to $608 \mathrm{kWh}$ decreased by the efficiency of the PSH) meaning that a limit for such a WT-PSH configuration has been reached. Therefore, it seems that there is no need to oversize the proposed system in terms of its energy storage capacities. This is supported by the mean upper reservoir state of filling depicted in Figure 6, which decreases with an increasing maximal reservoir storing capacity. Such a situation indicates the underutilisation of the available storing potential.

In Figure 7 we have visualised the operation of the WT-PSH energy source in January 2014, 2015, and 2016. As can be seen, the greater volume of scheduled generation from the PSH is usually preceded by an increase in wind generation, indicating that the scheduling formula correctly interprets both wind generation forecasts and the predicted upper reservoir state of filling, and makes correct decisions when it comes to the energy generation schedule. 


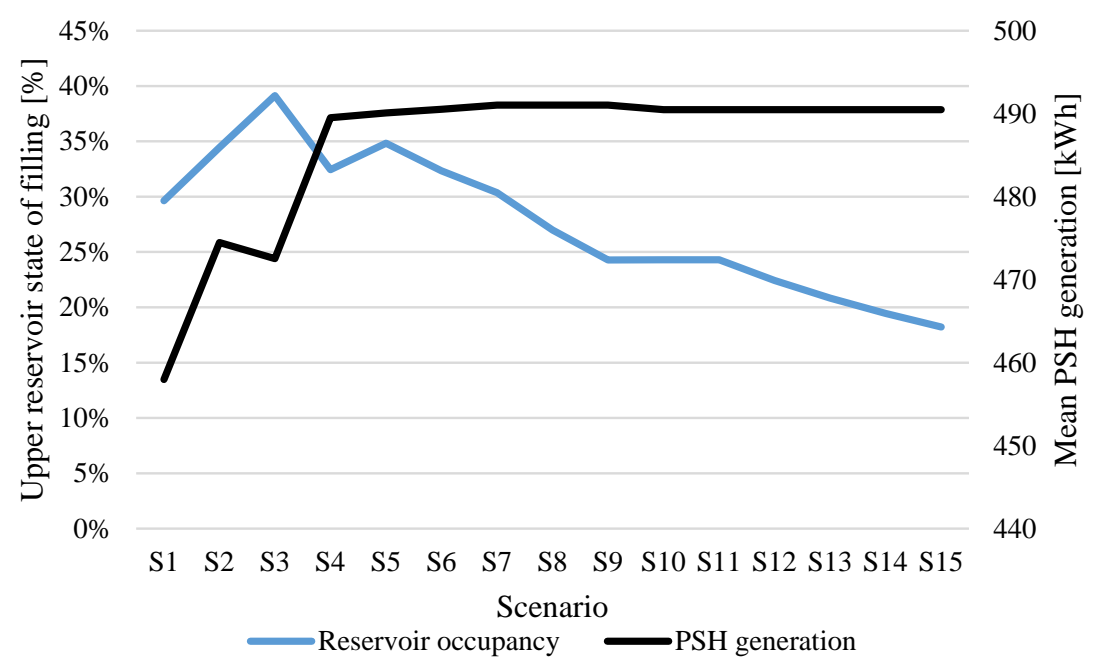

Figure 6. Mean values of the upper reservoir state of filling and the PSH generation over the years 2014-2016.
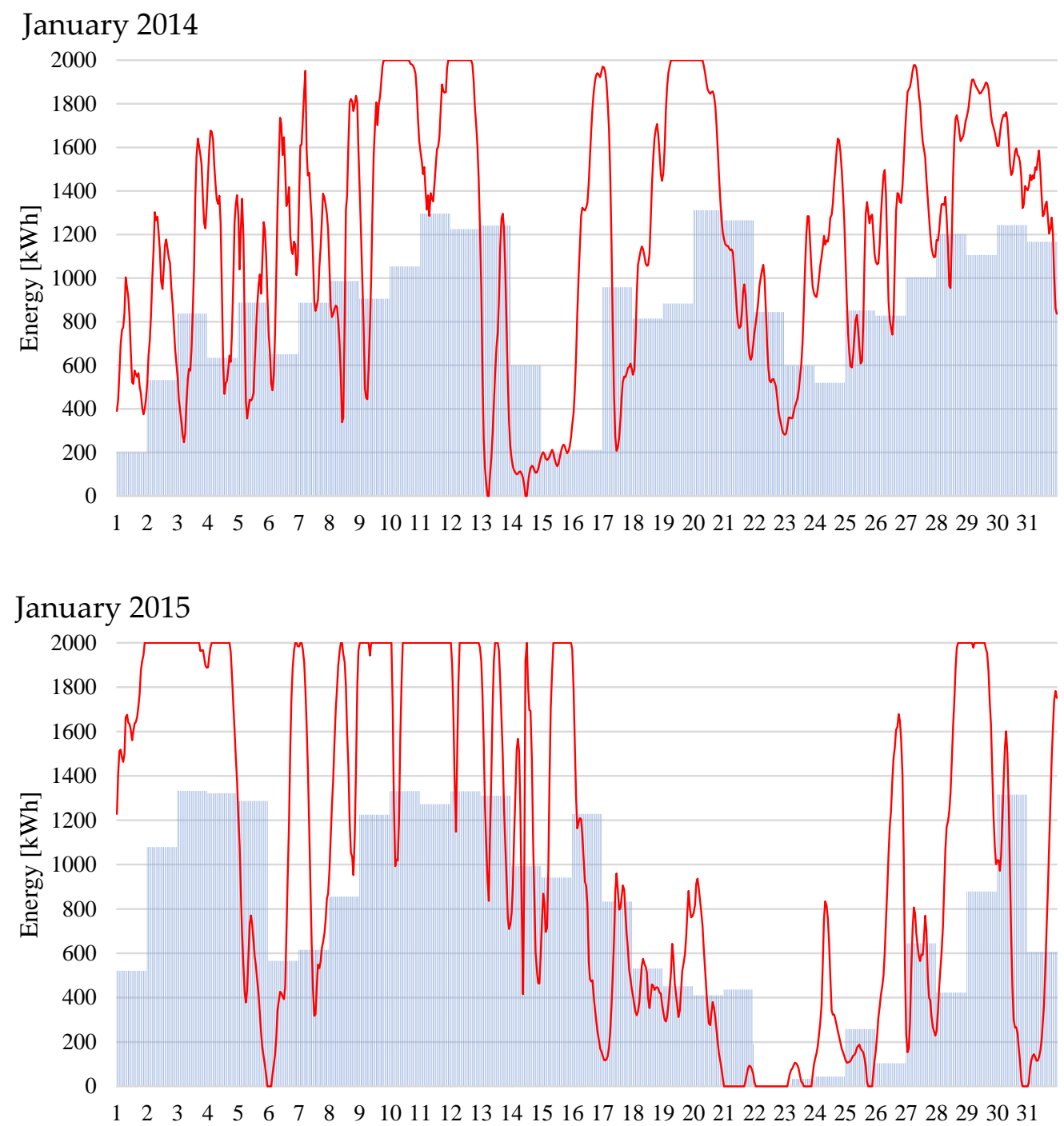

Figure 7. Cont. 


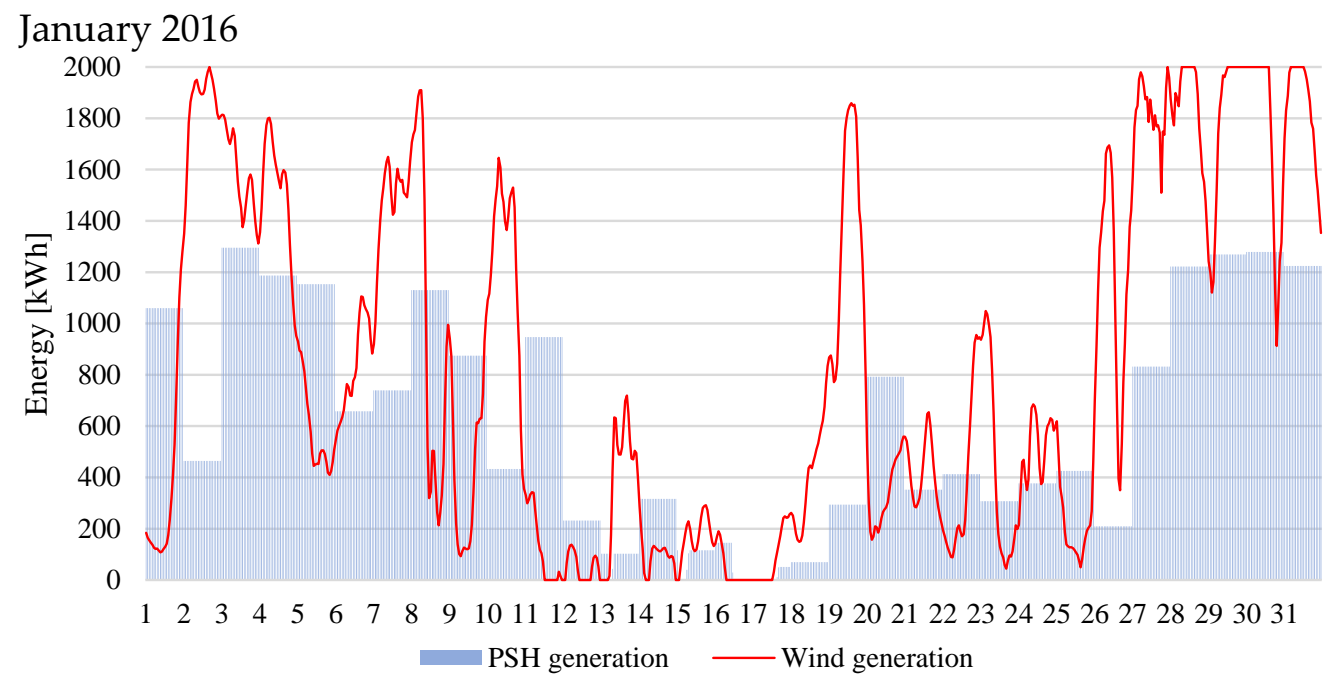

Figure 7. Operation of the WT-PSH hybrid in scenario S4. $X$ axis: days.

\subsection{Sensitivity Analysis}

In the optimisation model we have considered three parameters which may impact the operation of the WT-PSH energy source. All of them have a potential impact on the accuracy of the scheduling formula as well as the volume of the rejected energy from the wind generation. Figure 6 summarises that impact. On each of the charts we have visualised all possible combinations of those parameters with a stress on the individual parameter given on the $X$ axis.

As can be seen, an increase in the $\alpha$ parameter generally leads to an increase in the MAPE error and a decrease in the rejected volume of energy from wind generation. This results from the fact that this parameter in the scheduling formula refers to the volume of energy from the forecasted wind generation which should be considered in the schedule for the next 25 to $48 \mathrm{~h}$. Low values of $\alpha$ make it possible to avoid errors in scheduling (MAPE) whereas those close to 1.0 will be prone to errors. At the same time, $\alpha$ close to zero will neglect some portion of the forecasted wind generation and, in some circumstances (e.g., upper reservoir is almost full), that energy will be rejected.

In the case of the beta parameter, which determined the usage of the predicted upper reservoir state of filling, one can observe similar dependencies, as in the case of the alpha parameter. However, it seems that regardless of the remaining parameters $\left(\alpha, V^{M}\right)$ for values of $\beta$ ranging from 0 to 0.3 the error of the forecasting approach is relatively low and remains below $10 \%$. An increase in the $\beta$ value leads to a simultaneous increase in the MAPE criterion. This results from the fact that the upper reservoir state of filling is a consequence of the previously created schedule and the forecasted energy yield from wind turbines. It is important to note that by increasing the utilisation of the upper reservoir in the scheduling formula the volume of rejected energy from wind generation dwindles. This results from the fact that the scheduling formula with $\beta$ close to 1 will always tend to discharge almost all available energy in the next considered period and, as a consequence, there will almost always be a possibility to store there the energy originating from wind generation.

The upper reservoir capacity $\left(V^{M}\right)$ seems not to have any significant impact on the value of the MAPE criterion. However, a slight decrease in energy rejected from the wind generation is observed when the upper reservoir energy storage capacity increases. Naturally, it is not observed in all configurations of $\alpha$ and $\beta$. For some, regardless of the $V^{M}$ value, the share of rejected energy is still above $10 \%$, or even close to $90 \%$. This occurred for very low values of both of these parameters. Regression analysis conducted for the $V^{M}$ impact on the share of the rejected energy from WT generation shows that, on average, with every increase of $1 \mathrm{MWh}$ in the upper reservoir capacity one should expect the volume of the rejected energy to decrease by $0.06 \%$. 
The correlation analysis between the objective function and the volume of the rejected energy from wind generation revealed a rather loose negative interdependence. The average coefficient of correlation (CC) for all considered combinations of input variables was -0.38 (Figure 8). Interestingly, the highest were observed for the combinations with relatively low upper reservoir capacities. For $V^{M}$ $=21.6 \mathrm{MWh}$ the CC was -0.76 and tended to decrease with increasing reservoir capacity. This results from the fact that the upper reservoir energy storage capacity has the potential to compensate for forecasting errors and minimises the relation between the objective function and the imposed constraint-the volume of rejected energy from wind generation.

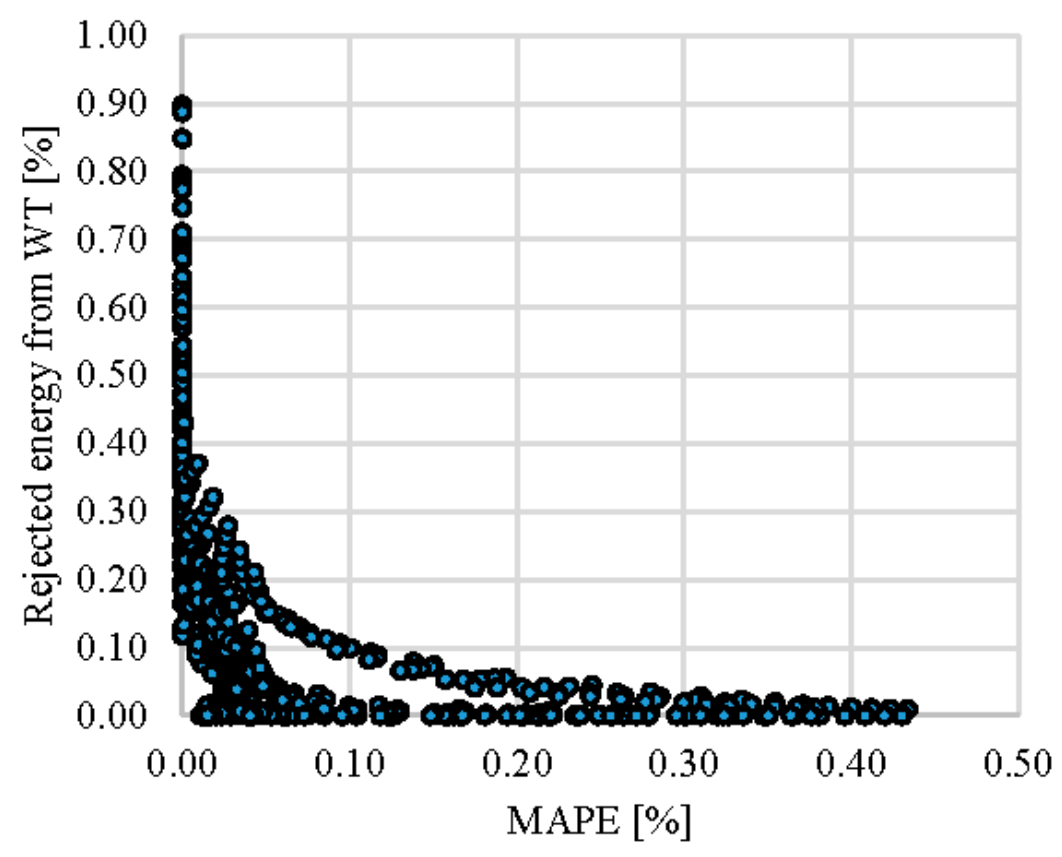

Figure 8. Relation between objective function (MAPE) and the constraint (percentage of rejected energy).

A similar correlation analysis has been conducted for the individual parameters and the aforementioned objective function and the volume of rejected energy from WTs. The obtained CC values are summarised in Table 1. Once again the resulting CC are rather low and, in the case of upper reservoir capacity $\left(V^{M}\right)$, rather insignificant when it comes to their relation with the objective function and the constraint. Greater values are observed for the $\alpha$ and $\beta$ parameters and they are coherent with the analysis made based on the scatter plots in Figure 9. An increase in $\alpha$ will generally lead to a decrease in the volume of rejected energy from WT generation and an increase in scheduling inaccuracy. Meanwhile, in the case of $\beta(C C=0.85)$ the higher the value, the higher the schedule error (MAPE) and the lower the volume of rejected energy (CC $=-0.35$, REJECTED), Table 2.

Table 2. Correlation coefficients between variables $\left(\alpha, \beta, V^{M}\right)$, objective function (MAPE), and constraint (REJECTED).

\begin{tabular}{ccc}
\hline & MAPE & Rejected \\
\hline$\alpha$ & 0.3915 & -0.5186 \\
$\beta$ & 0.8456 & -0.3568 \\
$V^{M}$ & -0.0215 & -0.1545 \\
\hline
\end{tabular}


$\operatorname{MAPE}(\alpha)$

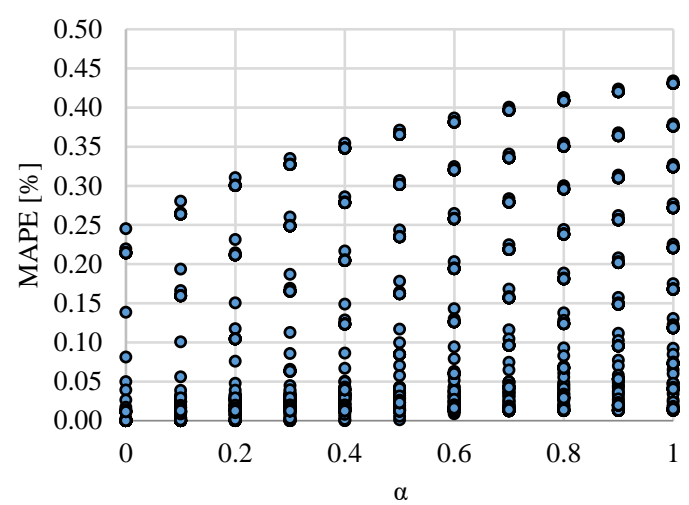

$\operatorname{MAPE}(\beta)$

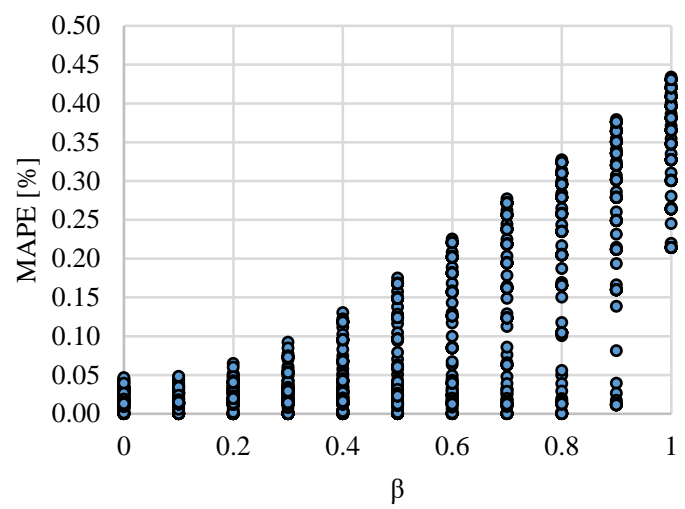

MAPE $\left(\mathrm{V}^{\mathrm{M}}\right)$

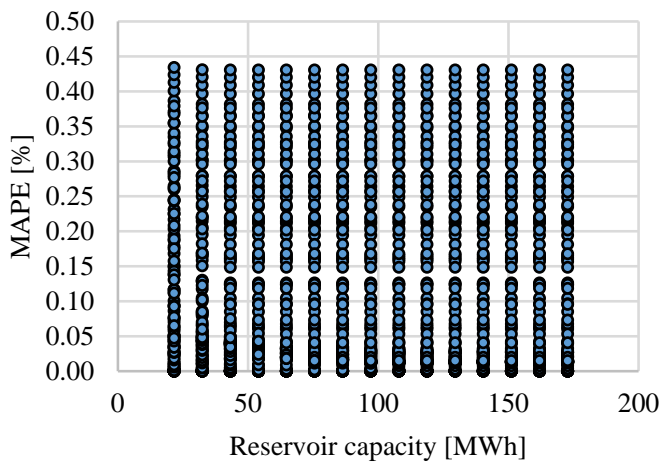

$\operatorname{REJECTED}(\alpha)$

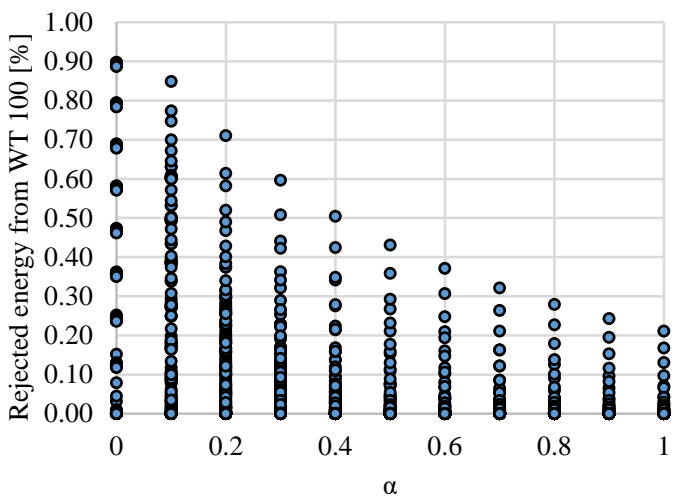

REJECTED $(\beta)$

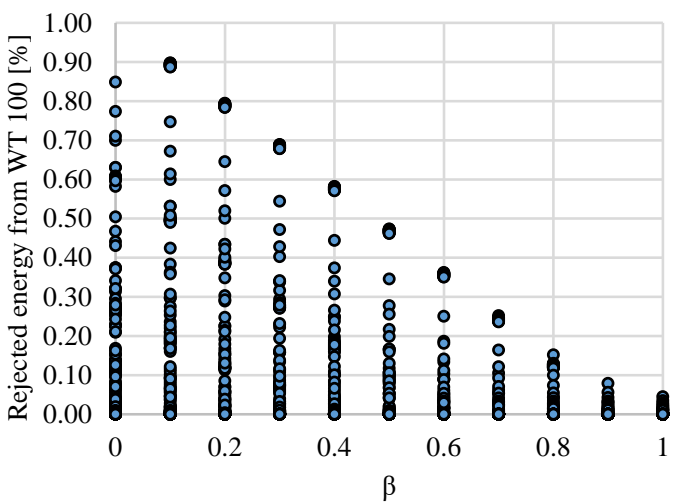

$\operatorname{REJECTED}\left(\mathrm{V}^{\mathrm{M}}\right)$

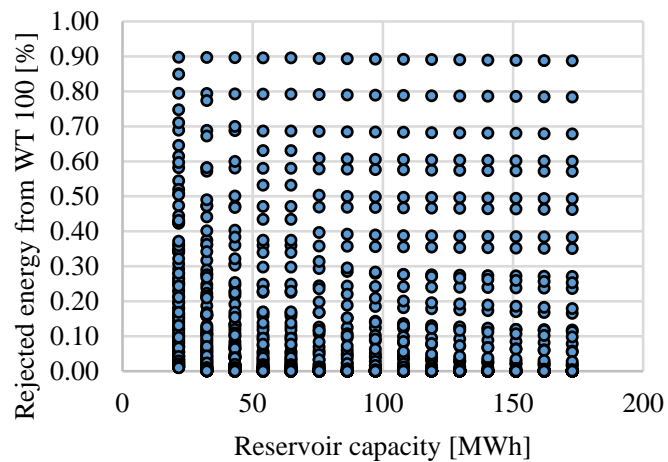

Figure 9. Objective function and the main constraint in the function of individual variables.

\subsection{Analysis of the Dispatch Errors}

As observed efigurearlier, the proposed scheduling/dispatching procedure is not error-free. Hereunder, we provide a concise analysis of observed absolute errors in the case of the considered scenarios. Their ordered values (from largest to smallest) are depicted in Figure 10. Please note that in scenarios S1 and S2 some errors occurred during $20 \%$ of the hours considered in our analysis, whereas in all the remaining scenarios it is significantly less than $2 \%$ or, in other words, there were no dispatch errors over more than $98 \%$ of the considered time period. This shows that for larger storage capacity the proposed scheduling method is very efficient, but a question arises whether it is, from 
an economic point of view, cost effective to invest in larger storage or accept potential penalties for unrealized dispatch.

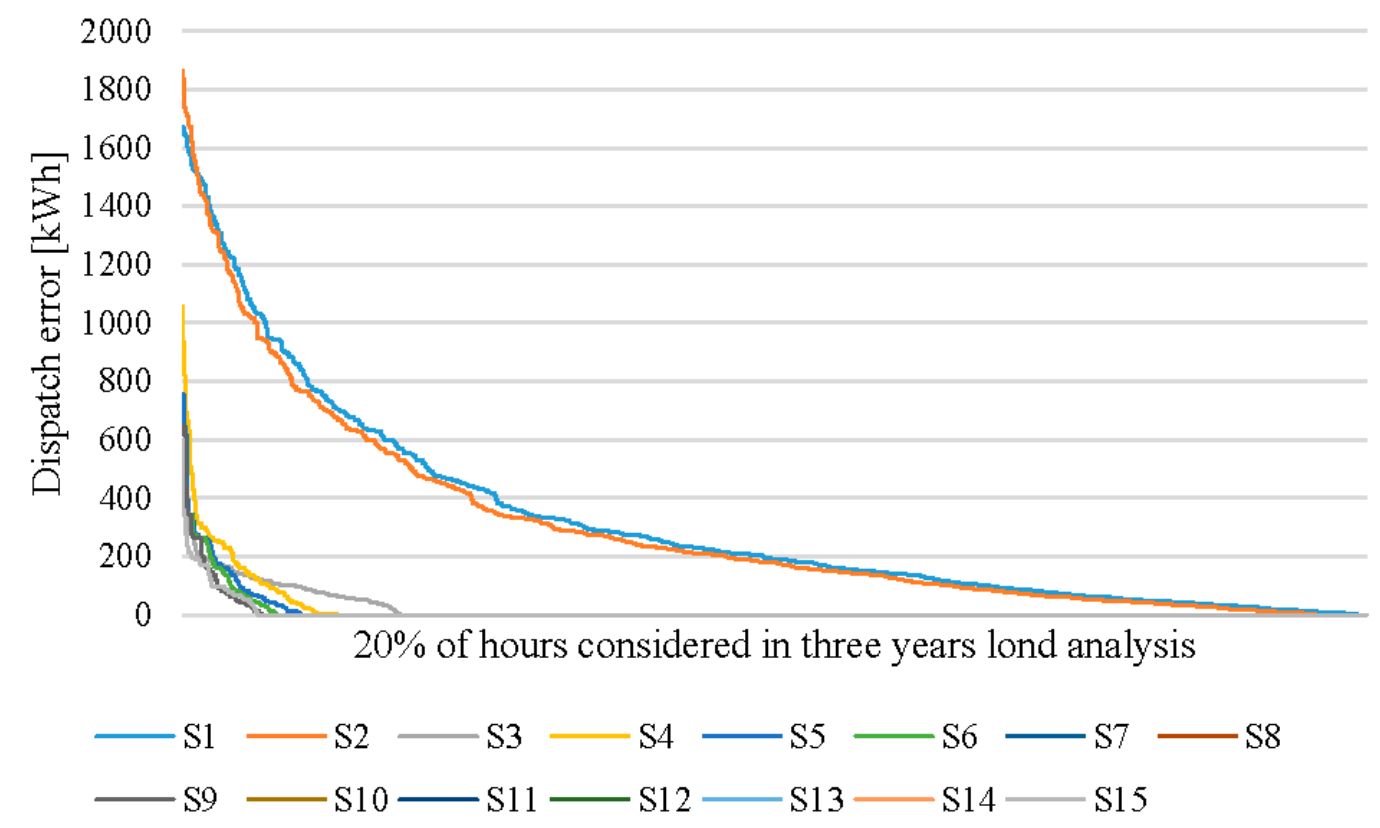

Figure 10. Ordered values of dispatch errors for 15 considered scenarios of upper reservoir capacity.

Further analysis of the dispatch errors focused on their statistical parameters. As can be observed in Table 3 there is a visible trend of decreasing values of dispatching errors for larger upper reservoir capacities. Not only is the average value significantly reduced, but also the observed standard deviation and, as a consequence, the coefficient of variation. The analysis of kurtosis and skewness shows that the error distributions are leptokurtic (with fatter tails) and are positively skewed (the distribution is concentrated on the left tail).

Table 3. Basic statistical parameters of observed dispatch errors.

\begin{tabular}{ccccccccc}
\hline Scenario & S1 & S2 & S3 & S4 & S5 & S6 & S7-S9 & S10-S15 \\
\hline AVG $(\mathrm{kWh})$ & 61.3 & 57.1 & 4.0 & 4.2 & 2.8 & 2.3 & 1.8 & 1.5 \\
STD $(\mathrm{kWh})$ & 199.3 & 191.7 & 25.9 & 38.3 & 28.0 & 25.4 & 23.0 & 16.2 \\
CV [\%] & $30.7 \%$ & $29.8 \%$ & $15.5 \%$ & $10.8 \%$ & $10.0 \%$ & $9.2 \%$ & $8.0 \%$ & $9.2 \%$ \\
Skeweness & 4.6 & 4.9 & 9.4 & 14.0 & 14.7 & 15.1 & 17.9 & 14.8 \\
Kurtosis & 23.7 & 27.5 & 123.1 & 250.1 & 272.7 & 280.1 & 390.7 & 285.7 \\
\hline
\end{tabular}

\section{Conclusions}

The advent of variable renewable energy sources made a significant change on the energy market. In NPSs with a high penetration of VRES generation, not only does the demand side of the energy market start to vary, but so too does the supply side. In general, based on the coefficient of variation, the variability of wind and solar generation is greater than that of energy demand. So far various approaches have been proposed to overcome this problem. In this paper a novel strategy for scheduling the operation of a wind turbine/park and pumped-storage hydroelectricity is presented. The proposed approach takes into account the forecasted energy generation from the wind turbines for the next $24 \mathrm{~h}$ and the estimated upper reservoir state of filling at the end of the upcoming day. Based on those estimates an energy generation schedule is formulated for the next 25 to $48 \mathrm{~h}$.

The developed strategy was tested based on a three-year hourly time series of wind speed and synthetic wind speed forecasts generated for the purpose of this paper. The results indicate that a 
scheduling formula for a 2-MW wind turbine and a PSH with an energy storing potential equal to $54 \mathrm{MWh}$ is capable of reducing the intraday variability (calculated based on the coefficient of variation) of energy generation from $31 \%$ to $1.15 \%$. The low value of CV for the WT-PSH energy source indicated the good quality of the scheduling approach and the fact that the inherently variable energy from wind generation becomes manageable. For this configuration, and the $\alpha$ and $\beta$ parameter values assumed in the scheduling formula, the MAPE criterion for the schedule accuracy was $2.39 \%$, whereas that considered for wind generation was $27 \%$.

The results also show that an increase in upper reservoir capacity above a certain volume does not have a significant impact on the performance of the considered energy source. However, the larger the reservoir, the lower the value of the MAPE criterion and the volume of rejected energy will be. This, however, comes at the cost of underutilised reservoir storage capacity. Therefore, the $\alpha$ and $\beta$ parameters, which are used in the scheduling formula, remain the most relevant.

There are several ways in which such an energy source may be used in the power system. First and foremost, it can be applied to increase the share of wind generation in covering the energy demand without increasing the variability of the supply side of the energy market. Secondly, the scheduling formula may be modified in such a way that the WT-PSH energy source will generate electricity only during peak hours. As a consequence it will operate as a conventional PSH power plant, but the generally greater energy prices during the peak demand periods will increase the economic potential of the wind energy. Finally, in systems with an already high penetration of VRES, this type of energy source can be used as a conventional power plant whose energy generation can be scheduled for the next 25 to $48 \mathrm{~h}$. Its reliability and availability mainly during the summer period (which has less beneficial wind speed conditions at the considered location) can be increased by coupling it with a PV installation.

In this paper we have made a new contribution by proposing a novel mathematical model for scheduling the operation of a wind-powered pumped-storage hydroelectric hybrid power source. Additionally, we have introduced a measure to assess the accuracy and quality of the scheduled generation and, based on the sensitivity analysis, we revealed the impact of the individual parameters on the performance of the WT-PSH. It is expected, by applying more accurate wind speed/generation forecasts, that the accuracy of the schedule generation will also increase.

Naturally, not all aspects of such an energy source operating in the very complex environment of the energy market have been investigated. From the author's perspective, the most important future research direction would be to investigate the economic side of such an energy source, as well as its potential in energy systems which depend on a share of VRES in covering energy demand.

Author Contributions: J.J. has retrieved the data, designed the experiment, performed the calculations and written the draft of the manuscript. Both authors have discussed the findings and agreed on the final form of the manuscript.

Funding: A. Kies is financially supported by the national R\&D project NetAllok, Methoden und Anwendungen der Netzkostenallokation (Bundesministerium für Wirtschaft und Energie, FKZ 03ET4046A).

Conflicts of Interest: The authors declare no conflict of interest. 


\section{Nomenclature}

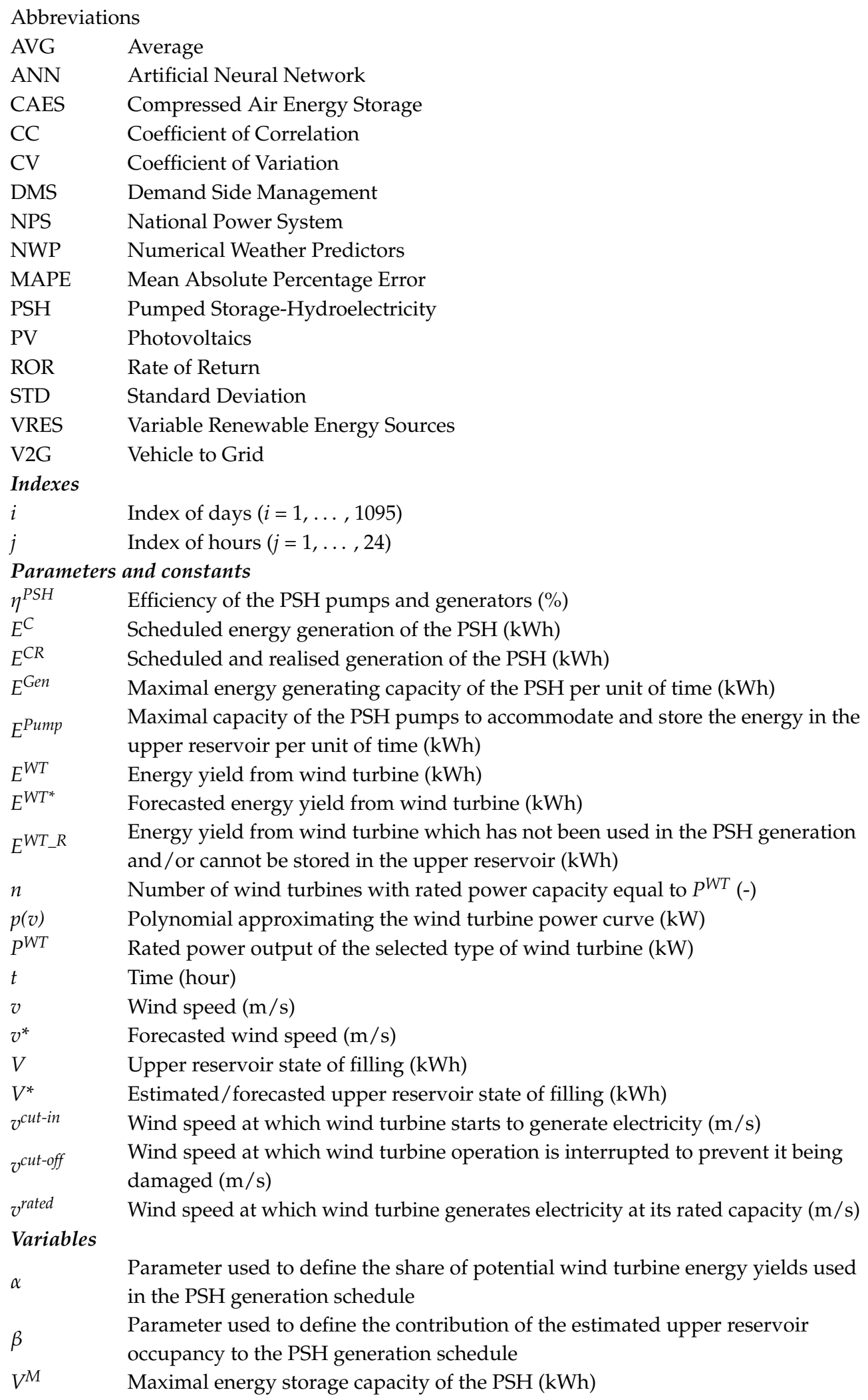




\section{References}

1. Suganthi, L.; Samuel, A.A. Energy models for demand forecasting-A review. Renew. Sustain. Energy Rev. 2014, 16, 1223-1240. [CrossRef]

2. Jung, J.; Broadwater, R.P. Current status and future advances for wind speed and power forecasting. Renew. Sustain. Energy Rev. 2014, 31, 762-777. [CrossRef]

3. Kyritsis, E.; Andersson, J.; Serletis, A. Electricity prices, large-scale renewable integration, and policy implications. Energy Policy 2017, 101, 550-560. [CrossRef]

4. Santos, S.F.; Fitiwi, D.Z.; Cruz, M.R.; Cabrita, C.M.; Catalão, J.P. Impacts of optimal energy storage deployment and network reconfiguration on renewable integration level in distribution systems. Appl. Energy 2017, 185, 44-55. [CrossRef]

5. Jones, L.E. Renewable Energy Integration: Practical Management of Variability, Uncertainty, and Flexibility in Power Grids; Academic Press: Cambridge, MA, USA, 2014.

6. Jacobson, M.Z.; Delucchi, M.A. Providing all global energy with wind, water, and solar power, Part I: Technologies, energy resources, quantities and areas of infrastructure, and materials. Energy Policy 2011, 39, 1154-1169. [CrossRef]

7. Delucchi, M.A.; Jacobson, M.Z. Providing all global energy with wind, water, and solar power, Part II: Reliability, system and transmission costs, and policies. Energy Policy 2011, 39, 1170-1190. [CrossRef]

8. Kaldellis, J.K.; Kapsali, M.; Kavadias, K.A. Energy balance analysis of wind-based pumped hydro storage systems in remote island electrical networks. Appl. Energy 2010, 87, 2427-2437. [CrossRef]

9. Kapsali, M.; Kaldellis, J.K. Combining hydro and variable wind power generation by means of pumped-storage under economically viable terms. Appl. Energy 2010, 87, 3475-3485. [CrossRef]

10. Kapsali, M.; Anagnostopoulos, J.S.; Kaldellis, J.K. Wind powered pumped-hydro storage systems for remote islands: A complete sensitivity analysis based on economic perspectives. Appl. Energy 2012, 99, 430-444. [CrossRef]

11. Kavadias, K.A.; Kapsali, M.; Kaldellis, J.K. An integrated computational method for the optimum sizing of a wind-based pumped hydro storage system. In Proceedings of the European Wind Energy Conference, Marseille, France, 16-19 March 2009.

12. Papaefthymiou, S.V.; Papathanassiou, S.A. Optimum sizing of wind-pumped-storage hybrid power stations in island systems. Renew. Energy 2014, 64, 187-196. [CrossRef]

13. Katsaprakakis, D.A.; Christakis, D.G.; Pavlopoylos, K.; Stamataki, S.; Dimitrelou, I.; Stefanakis, I.; Spanos, P. Introduction of a wind powered pumped storage system in the isolated insular power system of Karpathos-Kasos. Appl. Energy 2012, 97, 38-48. [CrossRef]

14. Katsaprakakis, D.A. Hybrid power plants in non-interconnected insular systems. Appl. Energy 2016, 164, 268-283. [CrossRef]

15. Anagnostopoulos, J.S.; Papantonis, D.E. Pumping station design for a pumped-storage wind-hydro power plant. Energy Convers. Manag. 2007, 48, 3009-3017. [CrossRef]

16. Ma, T.; Yang, H.; Lu, L. Feasibility study and economic analysis of pumped hydro storage and battery storage for a renewable energy powered island. Energy Convers. Manag. 2014, 79, 387-397. [CrossRef]

17. Ma, T.; Yang, H.; Lu, L.; Peng, J. Pumped storage-based standalone photovoltaic power generation system: Modeling and techno-economic optimization. Appl. Energy 2015, 137, 649-659. [CrossRef]

18. Ma, T.; Yang, H.; Lu, L.; Peng, J. Optimal design of an autonomous solar-wind-pumped storage power supply system. Appl. Energy 2015, 160, 728-736. [CrossRef]

19. Hessami, M.A.; Bowly, D.R. Economic feasibility and optimisation of an energy storage system for Portland Wind Farm (Victoria, Australia). Appl. Energy 2011, 88, 2755-2763. [CrossRef]

20. Hedegaard, K.; Meibom, P. Wind power impacts and electricity storage-A time scale perspective. Renew. Energy 2012, 37, 318-324. [CrossRef]

21. Canales, F.A.; Beluco, A.; Mendes, C.A.B. A comparative study of a wind hydro hybrid system with water storage capacity: Conventional reservoir or pumped storage plant? J. Energy Storage 2015, 4, 96-105. [CrossRef] 
22. Murage, M.W.; Anderson, C.L. Contribution of pumped hydro storage to integration of wind power in Kenya: An optimal control approach. Renew. Energy 2014, 63, 698-707. [CrossRef]

23. Varkani, A.K.; Daraeepour, A.; Monsef, H. A new self-scheduling strategy for integrated operation of wind and pumped-storage power plants in power markets. Appl. Energy 2011, 88, 5002-5012. [CrossRef]

24. Tan, Z.F.; Ju, L.W.; Li, H.H.; Li, J.Y.; Zhang, H.J. A two-stage scheduling optimization model and solution algorithm for wind power and energy storage system considering uncertainty and demand response. Int. J. Electr. Power Energy Syst. 2014, 63, 1057-1069. [CrossRef]

25. Jurasz, J.; Mikulik, J. Scheduling opearation of wind powered pumped-storage hydroelectricity. In Proceedings of the 13th International Conference on Industrial Logistics, Zakopane, Poland, 28 September-1 October 2016; AGH University of Science and Technology: Kraków, Poland, 2016; pp. 74-83.

26. Castronuovo, E.D.; Lopes, J.P. On the optimization of the daily operation of a wind-hydro power plant. IEEE Trans. Power Syst. 2004, 19, 1599-1606. [CrossRef]

27. Papaefthimiou, S.; Karamanou, E.; Papathanassiou, S.; Papadopoulos, M. Operating policies for wind-pumped storage hybrid power stations in island grids. IET Renew. Power Gener. 2009, 3, $293-307$. [CrossRef]

28. Helseth, A.; Gjelsvik, A.; Mo, B.; Linnet, U. A model for optimal scheduling of hydro thermal systems including pumped-storage and wind power. IET Gener. Transm. Distrib. 2013, 7, 1426-1434. [CrossRef]

29. Soman, S.S.; Zareipour, H.; Malik, O.; Mandal, P. A review of wind power and wind speed forecasting methods with different time horizons. In Proceedings of the North American Power Symposium (NAPS), Arlington, TX, USA, 26-28 September 2010; IEEE: Piscataway, NJ, USA, 2010; pp. 1-8.

30. Makridakis, S.; Wheelwright, S.C.; Hyndman, R.J. Forecasting Methods and Applications; John Wiley \& Sons: Hoboken, NJ, USA, 2008.

31. Zhao, W.; Wei, Y.M.; Su, Z. One day ahead wind speed forecasting: A resampling-based approach. Appl. Energy 2016, 178, 886-901. [CrossRef]

32. Dong, L.; Wang, L.; Khahro, S.F.; Gao, S.; Liao, X. Wind power day-ahead prediction with cluster analysis of NWP. Renew. Sustain. Energy Rev. 2016, 60, 1206-1212. [CrossRef]

33. Azimi, R.; Ghofrani, M.; Ghayekhloo, M. A hybrid wind power forecasting model based on data mining and wavelets analysis. Energy Convers. Manag. 2016, 127, 208-225. [CrossRef]

34. Miettinen, J.J.; Holttinen, H. Characteristics of day-ahead wind power forecast errors in Nordic countries and benefits of aggregation. Wind Energy 2017, 20,959-972. [CrossRef]

35. Korkas, C.D.; Baldi, S.; Michailidis, I.; Kosmatopoulos, E.B. Occupancy-based demand response and thermal comfort optimization in microgrids with renewable energy sources and energy storage. Appl. Energy 2016, 163, 93-104. [CrossRef]

36. Baldi, S.; Karagevrekis, A.; Michailidis, I.T.; Kosmatopoulos, E.B. Joint energy demand and thermal comfort optimization in photovoltaic-equipped interconnected microgrids. Energy Convers. Manag. 2015, 101, 352-363. [CrossRef]

37. Jurasz, J.; Mikulik, J.; Krzywda, M.; Ciapała, B.; Janowski, M. Integrating a wind-and solar-powered hybrid to the power system by coupling it with a hydroelectric power station with pumping installation. Energy 2018, 144, 549-563. [CrossRef]

38. Jurasz, J.; Ciapała, B. Integrating photovoltaics into energy systems by using a run-off-river power plant with pondage to smooth energy exchange with the power gird. Appl. Energy 2017, 198, 21-35. [CrossRef]

39. Yang, Z.; Liu, P.; Cheng, L.; Wang, H.; Ming, B.; Gong, W. Deriving operating rules for a large-scale hydro-photovoltaic power system using implicit stochastic optimization. J. Clean. Prod. 2018, 195, 562-572. [CrossRef]

40. Moustris, K.P.; Zafirakis, D.; Alamo, D.H.; Medina, R.N.; Kaldellis, J.K. 24-h Ahead Wind Speed Prediction for the Optimum Operation of Hybrid Power Stations with the Use of Artificial Neural Networks. In Perspectives on Atmospheric Sciences; Springer International Publishing: Basel, Switzerland, 2017; pp. 409-414.

41. Siemens Gamesa Renewable Energy. Available online: http://www.gamesacorp.com/ (accessed on 20 January 2017). 
42. Jurasz, J. Modeling and forecasting energy flow between national power grid and a solar-windpumped-hydroelectricity (PV-WT-PSH) energy source. Energy Convers. Manag. 2017, 136, 382-394. [CrossRef]

43. National Aeronautics and Space Administration Goddard Space Flight Center. Available online: https: / / gmao.gsfc.nasa.gov/reanalysis/MERRA-2/ (accessed on 20 January 2017). 